\title{
Resenha
}

Amoroso, Marta e Santos, Gilton Mendes dos (orgs). Paisagens Ameríndias: lugares, circuitos e modos de vida na Amazônia. São Paulo, Terceiro Nome, 2013, 344 pp.

\section{Três perspectivas sobre natureza e sociedade na Amazônia}

Nádia Heusi Silveira

INCT Brasil Plural

O título Paisagens Ameríndias diz muito sobre o que se lerá nessa coletânea. Uma das evidências que transpassa todas as partes do livro é a centralidade da rede fluvial como referência em torno da qual se desenvolvem a vida indígena e os mais variados temas contidos no livro. Os autores localizam os rios, igarapés e lagos onde estão os grupos pesquisados, bem como as relações econômicas, rituais, políticas e xamânicas que são ativadas na interação com a floresta, a partir dessa referência. Mesmo os indígenas que vivem em Manaus não deixam de se relacionar desde suas comunidades de origem, referenciadas pelos rios, com as quais estabelecem circuitos que indigenizam a cidade (:70, Magnani e Andrade).

O ambiente amazônico ganha destaque como paisagem, trazendo ao primeiro plano seu magnífico manancial de águas que ligam ou separam povos indígenas, regiões e ecossistemas, ainda que grande parte dos 10 povos de que tratam os artigos habite o espaço que corresponde ao estado do Amazonas. A opção mais institucional de trabalhar com os povos que vivem nos limites amazonenses feita pelos pesquisadores da Universidade Federal do Amazonas, ao propor uma cooperação acadêmica com antropólogos da Universidade de São Paulo -se houve -não repercute mais além desse recorte pragmático. As divisões geopolíticas entre municípios e estados perdem relevo nas etnografias, pois para produzir reflexões significativas sobre essa parte da região amazônica as escalas utilizadas são outras. 
Por ser a principal referência para as relações da vida diária, além de fonte de orientação espacial, essa paisagem geográfica formada pela rede fluvial e interflúvios também é abordada como coletivações de gente, espíritos, animais, plantas, minerais, objetos e fenômenos (:8, Amoroso e Santos). As paisagens são ameríndias pela posição que se busca aproximar, numa leitura do espaço e das relações que tende a perspectivas simétricas ou cruzadas às dos povos autóctones. Alteridade, sobretudo, é um conceito mobilizado mais ou menos centralmente nos argumentos ou elaborado nas descrições sobre os Enawene-Nawe, Sateré-Mawé, Mura, Tukano, Baniwa, Waimiri-Atroari, Suruwaha, Deni, Jarawara e Paumari apresentadas ao leitor.

O intercâmbio acadêmico entre UFAM e USP, do qual resultou esta coletânea, previu três linhas de pesquisa que aparecem como partes no livro: Paisagens, circuitos e lugares na Amazônia; Coletivos e pessoas no Alto Rio Negro; e Extrativismo e cosmologias no Médio Purus. Essas pesquisas, comentadas a seguir em ordem diversa da que aparece no livro, tiveram como projeto comum abordar o tema natureza e sociedade na Amazônia. A pluralidade dos conteúdos evocados sob o prisma das paisagens ameríndias é motivada tanto por questões teóricas como práticas e apresenta-se em variadas maneiras na relação pesquisador-pesquisado, em diferentes amplitudes de comparação, resultando em distintas propostas de investigação.

Na primeira parte, "Paisagens, circuitos e lugares na Amazônia", estão os estudos cuja proposta foi entender como os indígenas usam o tempo livre e quais suas formas de lazer nos espaços de socialidade das cidades amazônicas(:46, Magnani e Andrade). No entanto, essa parte se caracteriza mais por abordar os modos indígenas de habitar os lugares em que vivem. Os artigos tratam desde relações de vizinhança no interior da aldeia enawene-nawe (Silva), passando pelo modo como os Mura se diferenciam dos demais povos pela maneira de viver nas várzeas dos rios (Amoroso), para então chegar a Manaus e aos circuitos sateré-mawé (Magnani e Andrade; Tambucci et al.).

Apesar do acúmulo de etnografias realizadas na Amazônia nas últimas décadas, ainda há poucos materiais que tratam dos índios que vivem nas cidades. Manaus recebe indígenas majoritariamente do Alto Rio Negro e do leste do estado. Os Sateré-Mawé que estabeleceram comunidades nesta cidade vieram principalmente da Terra Indígena AndiráMarau, que abrange as cabeceiras dos rios Andirá e Maraú. Entre as atividades que permitem acessar a experiência desses indígenas em Manaus, destacam-se a produção de artesanato e a prática do futebol (:75, Tambucci et al.). Ambas são atividades que ocorrem sistematicamente, em torno das quais a paisagem da cidade é ocupada e mapeada, além de 
constituírem momentos significativos de troca entre si e com os brancos. O "peladão indígena”, em particular, é um evento que ressalta sutilezas das relações no campo interétnico expressas nas regras dos times de futebol.

O trânsito e os trajetos na busca de matérias-primas para confeccionar artesanatos, por exemplo, estende-se para além das várias comunidades sateré nos bairros de Manaus, incluindo comunidades em cidades vizinhas, como Parintins e Maués, e aquelas da terra indígena de origem. A vinculação desses diversos lugares sem contiguidade espacial salienta os circuitos sateré-mawé. É um aspecto empiricamente observável do seu modo de habitar a cidade que,para Magnani e Andrade (:69), acentua a importância dos deslocamentos e dos trajetos, em detrimento de uma residência estabilizada.

O artigo sobre os Mura também aponta para possíveis circuitos existentes entre as aldeias da Terra Indígena Cunhã-Sapucaia, na região do Baixo Rio Madeira, e as cidades de Borba e Autazes. Porém, Amoroso aborda o "sistema da beira" tendo por eixo a dimensão cosmopolítica do uso da expressão "caboclo" como um modo de autoidentificação mura. O termo contrasta, por um lado, com as categorias "branco" e "índio selvagem", e, por outro, "caboclo" também alude às relações entre humanos e não-humanos no xamanismo. No primeiro contexto, opera um tipo de cartografia das reminiscências de origem (:96). As transformações provocadas pelos ciclos extrativistas, ao longo do século $\mathrm{xx}$, fizeram com que a moradia dos grupos domésticos, dispersos na beira d'água, em casas flutuantes, assumisse o formato de aldeia. Assim, aqueles que não viveram em aldeias na infância eventualmente se autodenominam "caboclos" pela forma de habitação similar a estes.

Se a historicidade mura insinua-se na variação do português que utilizam e nas categorias da sua linguagem, entre os Enawene-Nawe ela também se expressa no aspecto espacial, só que na dinâmica da vicinalidade. Os clãs que vivem em Halataikwa, aldeia na região do Rio Juruena, observam a regra de residência uxorilocal. Por ter descendência patrilinear, essa regra tende a dispersar os membros de um clã enawene entre as casas da aldeia, porém, ele se mantém como grupo cerimonial. Silva examina as variações na conformação da aldeia no tempo, em termos da posição dos diversos clãs nas casas e das alianças matrimoniais, bem comoda distância da casa das flautas, para mostrar que as relações de vizinhança resultam de pequenos ajustes provocados por orientações de residência, descendência, rituais e de uma concepção cosmológica projetada no espaço aldeão; fatores que se combinam de modo imprevisível na história do grupo.

Em "Coletivos e pessoas no Alto Rio Negro", a parte seguinte, encontram-se etnografias realizadas no noroeste amazônico com o propósito de observar condições 
materiais da vida social indígena (:46, Magnani e Andrade).Os autores discutem práticas e conceitos indígenas evidenciados por princípios metodológicos diversos. Isto é, há pesquisa antropológica clássica ou algo assemelhado (Estorniolo; Vianna), pesquisa colaborativa (Montardo), pesquisa baseada em literatura etnográfica (Matarezio Filho) e formas híbridas ligadas a autoantropologia (Barreto et al.; Barreto e Santos). As paisagens ameríndias - e a diversidade de seres que abrigam - assumem ora uma ênfase maior em conhecimentos, ora em relações.

Os artigos com autoria indígena discutem conhecimentos tukano enfocando forma e conteúdo. É de notar que ambos mencionam o pensador tukano que orientou as reflexões. Barreto etal. discorrem sobre a noção úukuse ampliando o foco sobre esse conceito, margeando possibilidades e imagens explicativas, sem se valer somente da lógica argumentativa ocidental, num exercício "cruzado" de saberes (:117). Os autores trazem uma ótima figura esquemática dos coletivos indígenas do noroeste amazônico e seu mito de origem. Desse modo procuram demonstrar que as manifestações ocorridas na viagem da Canoa de Transformação não se atêm a fatos históricos apenas, pois também formalizam o pensamento e a ação que caracterizam a arte úukuse do diálogo, da narração.

Barreto e Lima concebem seu texto como um meio caminho entre narrativa mítica e teoria não elaborada (:127) sobre seres aquáticos. Em um plano taxionômico apresentam uma detalhada e extensa sistematização de como os Tukano classificam os peixes, waí, a partir das histórias de eventos de transformação. Em outro plano, de fundo ontológico, mostram como essas classificações e a própria existência dos peixes são interconectadas e, ao mesmo tempo, como os waí se distinguem de outros seres aquáticos, os waí-mahsã. Estes últimos são seres invisíveis que representam a fonte original dos conhecimentos tukano, particularmente aqueles dos especialistas kumu, yai e bayá.

Nos estudos sobre os Baniwa, o campo interétnico se destaca, embora nem todos os autores salientem a relação com os brancos em sua análise. Estorniolo e Vianna pesquisaram na Escola Pamáali, uma escola indígena fundada no Rio Içana com recursos de organizações não governamentais. Montardo reflete sobre um projeto de revitalização cultural em Itacoatiara-Mirim, apoiado igualmente por brancos ligados a órgãos de governo e organizações não governamentais.

Essa parte traz ainda as reflexões de Matarezio Filho sobre o rito waimiri-atroari de iniciação masculina. As etapas do ritual bahinja maryba são decodificadas pelas relações que os meninos estabelecem com pessoas e objetos ao longo do evento, as quais produzem afecções corporais e posições relacionais necessárias para transformá-los em “caçadores 
casadouros" (:196). O autor argumenta que o rito pode ser pensado como movimento de predação do exterior fundamental para produção dos kinja, da gente waimiri-atroari que vive na bacia do Rio Negro. Esse artigo, assim como o de Vianna, toma a noção de pessoa refinada pela abordagem perspectivista para acercar-se do sentido de um estado/condição peculiar entre os indígenas.

Vianna analisa o caso dos ataques de yóopinai, seres do mundo subterrâneo que habitam a região do Içana, entre os jovens baniwa que estudam em Pamáali. A escola não se localiza em uma comunidade indígena,apesar de estar no território baniwa, e os estudantes, oriundos de várias comunidades, alternam uma etapa bimensal na escola com igual período em suas casas. A recorrência da "doença no coração" provocada pelos yóopinai nesse lugar com características sociocosmológicas particulares, instiga a reflexão sobre conceitos baniwa de saúde e doença. A saúde é vista como um estado de diferenciação perspectiva e o estado alterado, a perda de consciência provocada pela captura do coração-alma, como um deslocamento da existência no sentido da alteridade, uma transformação reversível ou "alter-ação".

Para tratar das traduções e teorias que os Baniwa vêm desenvolvendo sobre o meioambiente, tanto quanto das "equivocações" (cf. Viveiros de Castro, 2004) que ocorrem entre estes e os técnicos brancos em torno da prática da piscicultura, Estorniolo também se vale do perspectivismo. Entretanto, quem propõe tal abordagem é um professor baniwa interessado na criação de peixes. O exercício de conceituação na escola mostrou que a tônica baniwa é multinaturalista, em oposição ao multiculturalismo e à concepção de natureza única, e última,dos técnicos. A autora observa que os brancos tendem a instrumentalizar os conhecimentos baniwa sobre meio-ambiente, ao passo queos Baniwa tendem a politizar o tema.

Por fim, expõe-se o Projeto Podáali, com o qual Montardo colaborou. Ele previa, entre outras ações, a transferência dos kuwai, instrumentos musicais sagrados, enterrados na comunidade Camarão, no Rio Ayari, para São Gabriel da Cachoeira. A família baniwa que esteve à frente desse projeto de revitalização cultural gerou polêmica, pois os instrumentos musicais incorporam o poder dos ancestrais míticos, o que traz perigo para os Baniwa, caso sejam movimentados ou tocados inapropriadamente. Ao final desistiram desse empreendimento, mas uma maloca foi erguida na cidade e essa "casa de conhecimento" atrai eventos e participantes de expressão nacional e internacional (:222). Montardo afirma que os Baniwa, através desse projeto e da musicalização, estão 
atualizando relações não apenas com seus ancestrais, mas também com o mundo dos brancos.

$\mathrm{Na}$ última parte, "Extrativismo e cosmologias no Médio Purus", os autores abordam narrativas arawa sobre o extrativismo ocorrido em séculos passados e documentos que registram o trabalho indígena na economia de aviamento. Os povos pertencentes à família linguística arawa vivem nos interflúvios dos rios Purus e Juruá, em seu curso médio, como também no território peruano. Estes povos estão entre os menos estudados pelos antropólogos amazonistas (:300, Maizza), portanto, a coletânea traz essa relevante contribuição, com etnografias sobre os Suruwaha (Suárez), Deni (Florido), Jarawara (Maizza) e Paumari (Vieira).

Esse conjunto de artigos é articulado por um foco comum, oferecendo um excelente panorama a respeito da intensidade dos efeitos provocados pelas frentes extrativistas na vida indígena e das múltiplas expressões que o modelo regional amazônico das relações por dívida produz na sociocosmologia arawa. A extração de sorva, seringa, copaíba, ovos de tartaruga, castanha, madeiras e outras riquezas da floresta, cujo potencial econômico tem impulsionado há centenas de anos o estreitamento das relações entre índios e brancos, desencadeou,paralelamente, uma disputa pela atribuição de sentidos ao território (:244, Cardoso).

Cardoso se debruça sobre a expedição ao Purus, ocorrida na metade do século XIX, concebida pelo presidente da recém-criada província do Amazonas para mapear riquezas e habitantes da região. A partir de documentos e estudos, particularmente dos registros do comandante João Coutinho sobre essa viagem, o autor traça os sentidos da alteridade seguindo um viés multifatorial e plurirrelacional (:239). Descrições nuançadas mostram as várias facetas das relações entre os donos de feitorias, comerciantes de regatões, trabalhadores migrados do nordeste e os diferentes grupos indígenas que habitavam a bacia do Rio Purus à época, estabelecidas a partir da intensificação de mudanças decorrentes doextrativismo regional.

Diante desse contexto histórico, certas categorias arawa são exploradas. Os dawa, subgrupos nomeados suruwaha,e a noção de manakuni entre os Deni remetem a redes de intercâmbio.Suárez afirma que a territorialidade é o elemento distintivo dos subgrupos suruwaha (:264), que são coletivos identificados também a um ancestral comum. Atualmente,os dawa não se manifestam na morfologia social suruwaha, mas explicitam modos de diferenciação, em dégradée, no contexto multicentrado da rede social arawa e para além dela. Florido, por sua vez, examina as situações em que ocorre manakuni, que os Deni 
traduzem como pagamento, as quais sempre implicam relações de antagonismo. As trocas que geram pagamento envolvem relações sexuais, casamento e aquisição de mercadorias. Entretanto, há diferenças na reciprocidade que aparecem associadas ao modelo de relação com os patrões.

Os artigos sobre os Jarawara e Paumari abordam a relação com a floresta, respectivamente por meio dos coletivos não-humanos com quem interagem e por práticas econômicas. Os Jarawara têm como referência de conduta ideal os inamati, forma humana das almas de vegetais e animais, cujas constantes relações belicosas são observadas pelos xamãs. Esse é o modelo de relações com os inimigos e patrões. Com os brancos de hoje esse ideal não se realiza, conforme Maizza, e as relações são muito variadas. No caso Paumari, a principal atividade é a pesca. Seu ciclo em rios, igarapés e lagos da bacia do Purus define deslocamentos sazonais e, no passado, o papel desses indígenas na economia de aviamento. Em sua contribuição, Vieira desenvolve ideias em torno da pesca do peixe-boi para ligar história e presente, bem como indicar que o engajamento nessa atividade depende do relacionamento com a paisagem.

Enfim, a coletânea como um todo oferece uma rica variação de formas de fazer antropologia sobre povos indígenas. Os matizes combinam distintos recortes da relação entre antropologia e história, metodologias e estilos de investigação variados, estudos de pesquisadores com mais ou menos experiência, diferentes equações entre dados etnográficos e teorias. Entre os autores e autoras, uns poucos deixam que a teoria sobrepuje a etnografia, destoando do conjunto. Embora seja favorável a uma "antropologia de ambições minimalistas", como fala Sáez (2009), em especial no sentido que "inclui um conhecimento objetivo, passível de debate e não apenas de opiniões incomensuráveis" (ibid.: 14), sei que esse estilo não é consensual.

Diante da sociodiversidade e biodiversidade amazônica que a coletânea explora, só poderia corresponder essa diversidade de antropologias ou "antropodiversidade". Esse detalhe faz pensar que Paisagens Amerindias mereceria um encarte de imagens para realçar seu valor. Com exceção das fotos e esquemas em Silva, da figura apresentada por Barreto etal. e de esquemas ilustrativos esparsos em outros artigos, não há imagens das paisagens no livro.

Por outro lado, a essa diversidade equivale certa continuidade geográfica e teórica entre os artigos. As abordagens dos autores exprimem a herança lévi-straussiana na antropologia amazonista, de acordo com Taylor (2011: 86), em termos de explorar a abertura para o Outro que caracteriza o pensamento ameríndio. Mas não se pode 
identificar uma vertente teórica a conduzir a coletânea como um todo, já que ela abarca três linhas de pesquisa bem distintas. Na primeira parte se destaca a proposta de comparação de estudos realizados em grandes centros urbanos, com abordagem teórico-metodológica da antropologia urbana, em contraponto aos estudos da etnologia indígena. Na última, as pesquisas de campo dialogaram bastante com materiais historiográficos a respeito do extrativismo regional, buscando entender as redes de intercâmbio e relações existentes. É na segunda parte do livro onde fica mais evidente a incorporação, nas etnografias, de um refinamento analítico fruto do debate a respeito do dualismo Natureza/Cultura que marca a produção etnológica nas últimas duas décadas, especialmente em categorias oriundas da obra seminal de Viveiros de Castro.

Em termos geográficos, as problemáticas regionais e o complicado mundo dos projetos e das políticas indigenistas ganham contornos definidos, embora muitas vezes apenas no plano descritivo. Além disso, a relevância empírica e conceitual da paisagem para os povos amazônicos, a natureza social do ambiente, bem como as disputas de sentido geradas pela exploração comercial e urbanização da paisagem são aspectos realçados nos artigos, mas também o são os desdobramentos dos debates atuais na etnologia indígena. A coletânea tem, digamos assim, contextura e relevos. É uma leitura que deve se tornar obrigatória para aqueles que buscam conhecer a realidade amazônica.

\section{Referências bibliográficas}

SÁEZ, Oscar C.

2009 "Por uma antropologia minimalista". Antropologia em Primeira Mão, Florianópolis, n.112: 1-16.

TAYLOR, Anne-Christine

2011 "Dom Quixote na América: Claude Lévi-Strauss e a antropologia americanista". Sociologia \& Antropologia, Rio de Janeiro, v.1, n.2: 77-90.

Viveiros de CASTRo, Eduardo

2004 "Perspectival Anthropology and the Method of Controlled Equivocation". Tipiti, v.2, n.1: 3-22. 